\title{
Ambiguity in guideline definitions introduces assessor bias and influences consistency in IUCN Red List status assessments
}

\author{
Matt W. Hayward ${ }^{1,2,3 *}$, Matthew F. Child ${ }^{4}$, Graham I. H. Kerley ${ }^{2}$, Peter A. Lindsey ${ }^{5,6}$, \\ Michael J. Somers ${ }^{3,7}$ and Bruce Burns ${ }^{8}$ \\ ${ }^{1}$ College of Natural Sciences, Bangor University, Bangor, UK, ${ }^{2}$ Centre for African Conservation Ecology, Nelson Mandela \\ Metropolitan University, Port Elizabeth, South Africa, ${ }^{3}$ Department of Animal and Wildlife Sciences, Centre for Wildlife \\ Management, University of Pretoria, Pretoria, South Africa, ${ }^{4}$ Endangered Wildlife Trust, Johannesburg, South Africa, \\ ${ }^{5}$ Panthera, New York, NY, USA, ${ }^{6}$ Department of Zoology and Entomology, Mammal Research Institute, University of Pretoria, \\ Pretoria, South Africa, ${ }^{7}$ Department of Animal and Wildlife Sciences, Centre for Invasion Biology, University of Pretoria, \\ Pretoria, South Africa, ${ }^{8}$ School of Biological Science, University of Auckland, Auckland, New Zealand
}

OPEN ACCESS

Edited by:

James Guy Castley,

Griffith University, Australia

Reviewed by:

Carlos Alberto Lopez Gonzalez, Universidad Autonoma de Queretaro,

Mexico

Fabiano Rodrigues De Melo, Universidade Federal de Goiás, Brazil

*Correspondence:

Matt W. Hayward,

College of Natural Sciences, Bangor University, Thoday Building, Deiniol Road, Bangor LL572UW, UK m.hayward@bangor.ac.uk

Specialty section: This article was submitted to Conservation

a section of the journal Frontiers in Ecology and Evolution

Received: 22 April 2015 Accepted: 09 July 2015

Published: 28 July 2015

Citation: Hayward MW, Child MF, Kerley GIH, Lindsey PA, Somers MJ and Burns B

(2015) Ambiguity in guideline definitions introduces assessor bias and influences consistency in IUCN

Red List status assessments.

Front. Ecol. Evol. 3:87.

doi: 10.3389/fevo.2015.00087
The IUCN Red List is the most widely used tool to measure extinction risk and report biodiversity trends. Accurate and standardized conservation status assessments for the IUCN Red List are limited by a lack of adequate information; and need consistent and unbiased interpretation of that information. Variable interpretation stems from a lack of quantified thresholds in certain areas of the Red List guidelines. Thus, even in situations with sufficient information to make a Red List assessment, inconsistency can occur when experts, especially from different regions, interpret the guidelines differently, thereby undermining the goals and credibility of the process. Assessors make assumptions depending on their level of Red List experience (subconscious bias) and their personal values or agendas (conscious bias). We highlight two major issues where such bias influences assessments: relating to fenced subpopulations that require intensive management; and defining benchmark geographic distributions and thus the inclusion/exclusion of introduced subpopulations. We suggest assessor bias can be reduced by refining the Red List guidelines to include quantified thresholds for when to include fenced/intensively managed subpopulations or subpopulations outside the benchmark distribution; publishing case studies of difficult assessments to enhance cohesion between Specialist Groups; developing an online accreditation course on applying Red List criteria as a prerequisite for assessors; and ensuring that assessments of species subject to trade and utilization are represented by all dissenting views (for example, both utilitarian and preservationist) and reviewed by relevant Specialist Groups. We believe these interventions would ensure consistent, reliable assessments of threatened species between regions and across assessors with divergent views, and will thus improve comparisons between taxa and counteract the use of Red List assessments as a tool to leverage applied agendas.

Keywords: threatened species, IUCN Red List, conservation assessment, status assessment process, mainland islands, fencing for conservation, metapopulation management 


\section{Introduction}

The Red List was developed in 1964 by the International Union for the Conservation of Nature (IUCN). Since then, it has become the best tool for measuring the extinction risk of species, and for reporting on biodiversity trends through the Red List index (Butchart et al., 2006). Inaccurate Red List assessments can thus confound reporting for the Aichi 2020 biodiversity targets set by the Convention on Biological Diversity, as well as misdirecting scarce conservation funding. Clearly, accurate and consistent Red Lists are crucial to conservation policy and success (but see Butchart et al., 2005).

The Red List guidelines have undergone multiple revisions since their inception to ensure that the assessment criteria are objective, explicit, robust, and repeatable (Mace and Lande, 1991; Mace et al., 1992; Rodrigues et al., 2006; Hayward, 2009b). The global Red List is now the most widely used and accepted authority on the conservation status of the world's biodiversity (Rodrigues et al., 2006), which is achieved by soliciting taxon experts to apply available population, distribution and threat data to five quantitative criteria to evaluate whether the species meets any of the extinction risk thresholds. Although the five main criteria are robust and clear, there are certain definitions (containing implicit sub-criteria) that need further revision. Global assessments are largely carried out by Specialist Groups (SGs) under the umbrella of the Species Survival Commission (SSC). However, non-SG members are also used, especially during national assessments.

Inconsistencies in applying the Red List criteria can be distilled into two broad situations resulting from the lack of quantified guidelines (Figure 1): subconscious and conscious bias. For the former, assessor bias is largely a technical issue where the IUCN guidelines are unclear or ambiguous and thus lead to varying interpretations by the SG members based on Red Listing (in)experience. Subconscious bias can be improved through more detailed guidelines with quantified and robust thresholds for sub-criteria (similar to the five primary quantitative criteria) combined with online training modules and accreditation. More worryingly, however, are conscious biases based on personal values or agendas that creep in, especially from non-SG members, and may signify the increasing politicization of Red List assessments to leverage distinct agendas, particularly when the species is subject to trade or utilization and its Red List status may influence the legislation and regulation of such activities. Additionally, conscious bias may enter when there is a perceived correlation between conservation funding and the conservation assessment of a species, such that assessors may be reluctant to downlist a threatened species from fear of reduced funding for the project. This bias may be symptomatic of the broader issue of conservation investment driving conservation research (Bakker et al., 2010; Ahrends et al., 2011), and may account for overly precautionary assessments in many cases.

Such biases will need proactive mitigation by the IUCN. We discuss how and why biases occur by discussing examples for two major sources of Red List subjectivity: fenced subpopulations and benchmark distributions. (Throughout, we use "subpopulation" as defined by IUCN Standards and Petitions Subcommittee, 2014; but acknowledge that this would more likely be defined as a "population" in a strictly ecological sense).

\section{Fenced Subpopulations}

Red List assessments measure conservation status based on population numbers of wild and mature individuals for a specific taxon (IUCN Standards and Petitions Subcommittee, 2014). There is a dichotomy in deciding whether fenced subpopulations contribute to conserving a taxon or not, and this needs to be resolved. Uncertainty often arises regarding which fenced subpopulations constitute wild individuals with conservation value and which are intensively managed subpopulations akin to livestock. Central to delineating this issue is what determines a "self-sustaining" subpopulation. A definition of self-sustaining is being "able to provide for your own needs without help from others" (Delbridge and Bernard, 1995). The technical guidelines for deciding on which fenced subpopulations to include has been refined by the IUCN over time. For example, IUCN (2001), in the section entitled "Taxonomic level and scope of the categorization process," states:

"The categorization process should only be applied to wild subpopulations inside their natural range, and to populations resulting from benign introductions."

Similarly, the Red List Guidelines Version 8 (IUCN Standards and Petitions Subcommittee, 2010), state:

\begin{abstract}
"In addition to taxa within their natural range and subpopulations resulting from benign introductions (outside the taxon's natural range), the criteria should also be applied to self-sustaining translocated or re-introduced subpopulations (within the taxon's natural range), regardless of the original goal of such translocations or re-introductions. In such cases, the listing should indicate whether all or part of the assessed population has been introduced. Subpopulations introduced for nonconservation purposes, outside the natural range of the taxon are not assessed globally, but they may be assessed regionally (see Regional Guidelines, page 11).”
\end{abstract}

Finally, the Red List guidelines Version 11 (IUCN Standards and Petitions Subcommittee, 2014) provide more workable thresholds:

\footnotetext{
"Subpopulations of many species are dependent on conservation measures (such as protected areas) that are largely directed at mitigating human impacts. Such conservation-dependent (or, conservation reliant) subpopulations are generally considered "wild" and the data from such subpopulations are used in Red List assessments. In between these are subpopulations that are managed at moderate levels of intensity (Redford et al., 2011). For these subpopulations, the definition of wild may be based on the intensity of management, and the expected viability of the subpopulation without such management. Subpopulations dependent on direct intervention are not considered wild, if they would go extinct within 10 years without "intensive" management, such as:
} 
- Providing most of the food needs of most individuals in the subpopulation;

- Regularly supplementing the population from captive stock to prevent imminent extinction;

- Breeding manipulations, such as cross-fostering and downbrooding [e.g., removing extra chicks from large broods and giving to foster parents (Powell and Cuthbert, 1993); or transferring marsupial pouch young from a threatened to a common species (Taggart et al., 2005)];

- Providing ongoing, intensive veterinary care to most individuals.

Managed subpopulations are considered wild if the management is for counter-acting the effects of human threats, such as

- Protected areas;

- Anti-poaching patrols;

- Providing artificial shelters (e.g., nest boxes for birds, roosting sites for bats);

- Providing preventative treatments against disease outbreaks;

- Preventing natural vegetation succession in order to maintain the species' habitat;

- Translocating individuals between existing subpopulations;

- Control measures against non-native competitors or predators, including the establishment of exclusion fences, such as those used to keep out invasive predators;

- Control measures against native competitors or predators if such species have increased because of human activities (e.g., removing cowbirds Molothrus spp. or noisy miners Manorina melanocephala, which have increased because of habitat fragmentation and thereby threaten other native species Clarke and Grey, 2010);

- Occasionally supplementing the population from captive stock to increase genetic variability."

Thus, although the guidelines are becoming clearer and more practical for determining when to include fenced subpopulations, some technical issues still need to be resolved:

1. Quantifying the thresholds. For example, what frequency constitutes "regular" supplementation from captive stock and what frequency is desirable given the often harmful effects of re-stocking (Champagnon et al., 2012)? What proportion constitutes providing the food or water requirements for most individuals in a subpopulation? What frequency of translocation/reinforcement is acceptable? Is the proportion of the habitats within a fenced area used by the target species sufficient to allow the individuals to undertake the full range of behaviors of the species?

2. Identifying suitable management actions. Depending on the conservation objectives of a population, we need to resolve the paradox that subpopulations that are not selfsustaining but are managed "for conservation" (for example, via metapopulation management) are included, whilst those that are intensively managed for commercial purposes are excluded. For example, if control of introduced predators to protect threatened species is acceptable (e.g., Hayward et al., 2003), is the control of native predators to protect rare antelopes similarly acceptable, if the argument that native predators exist at artificially high numbers due to habitat disturbance is used (e.g., Hervieux et al., 2014)? Both scenarios would contribute to an increase in numbers of the focal species, but may have different implications for biodiversity. Can selectively bred individuals (e.g., to increase desirable traits for trophy hunting) also be considered wild if conservation breeding programmes also selectively breed [e.g., more docile individuals may be more likely to breed in captive environments (i.e., domestic selection; Lynch and O'hely, $2001 \mathrm{cf}$ management for genetic heterogeneity)]? If modifying the habitat to protect one species impacts on the overall biodiversity of the ecosystem, is this management action acceptable?

The lack of explicit quantitative thresholds and clear justifications for appropriate management techniques for the inclusion of fenced subpopulations has led assessors from different regions to almost arbitrarily include or exclude subpopulations, even when there is reliable information on them. For example, some Australian IUCN Red List species authorities ignore subpopulations conserved in fenced "mainland islands" (fenced areas of natural habitat where introduced species are excluded) due to the perception that they are not self-sustaining. Most translocations to fenced "mainland islands" in Australia are of threatened mammals moved to areas within the former ranges of the species concerned (Short, 2009) or mainland island fences have been created at sites with threatened species already present (e.g., Perup in Western Australia for woylies Bettongia penicillata, inter alia). In most cases, these re-established subpopulations persist and increase without being provided with supplementary food, so in this context are self-sustaining, but they would decline rapidly if the fences were not maintained and if predator incursions were not quickly detected and eradicated (Hayward et al., 2014). So clearly fencing is critical for the survival of these subpopulations, as the presence of introduced predators is the key threatening process for most species within a critical weight range of $35 \mathrm{~g}-5.5 \mathrm{~kg}$ (Burbidge and McKenzie, 1989), but they are still wild populations.

Conversely, in New Zealand, subpopulations in fenced "mainland islands" are currently considered in assessments of conservation status (e.g., Miskelly et al., 2008). Furthermore, some species statuses have improved over time with conservation management that has included, but has not been restricted to, fenced subpopulations (Gummer et al., 2015). For example, the conservation status of Otago Oligisoma otagense and grand skinks $O$. grande improved from Nationally Critical to Nationally Endangered between 2009 and 2012 as a result of successful conservation management that included protecting some populations within pest-proof fenced areas and others in areas subject to landscape-scale predator control networks (Reardon et al., 2012; Hitchmough et al., 2013), although the former remains Endangered on the IUCN Red List (Chapple, 2010) and the latter's assessment is out of date. Hitchmough (2013) also lists 12 mammal, bird, or invertebrate species that improved in national conservation status between 2005 and 2008-2011-five of these species included translocation to 


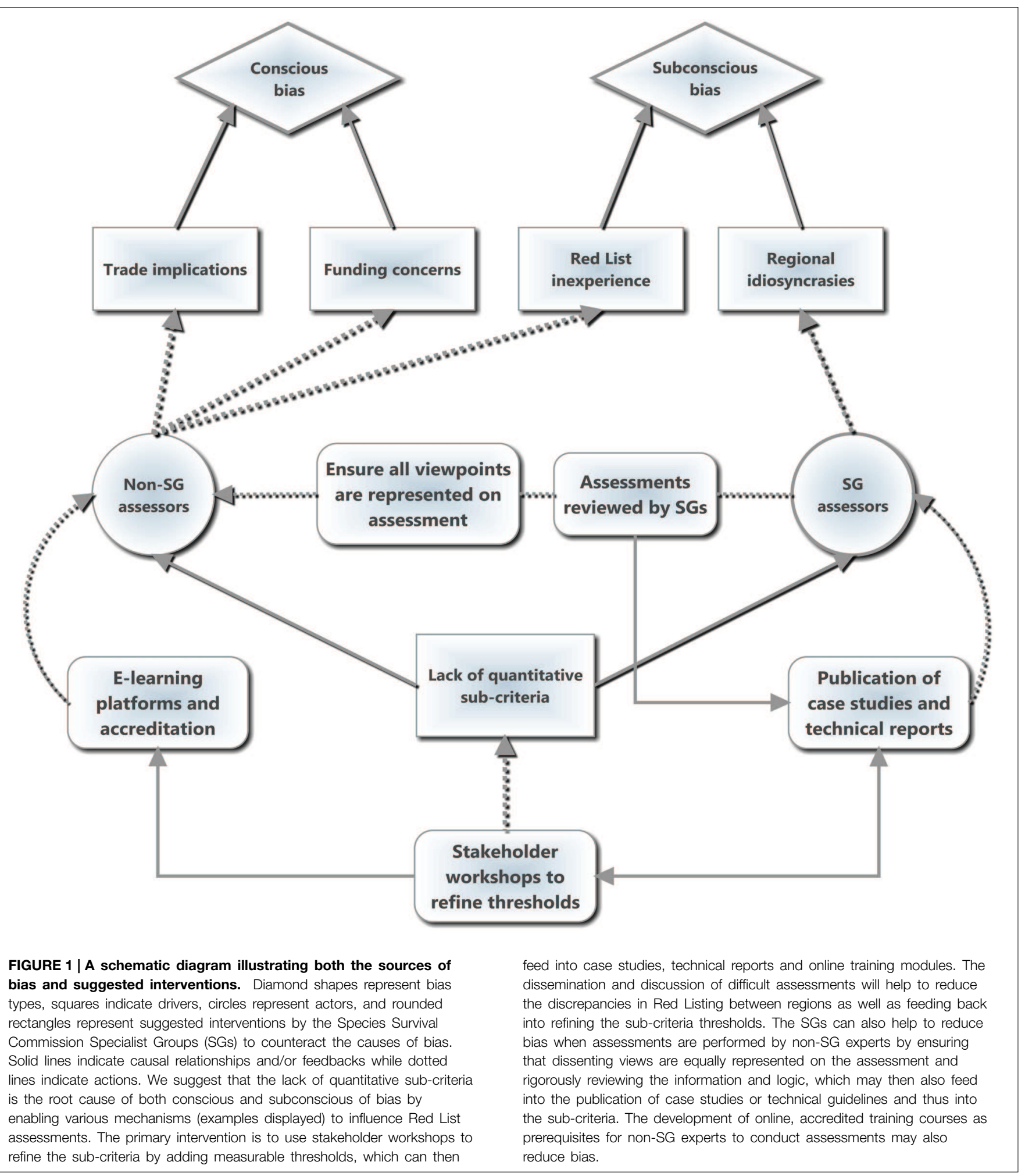

fenced "mainland islands" amongst the range of conservation management interventions used for each species. An example of one of these species is the brown teal Anas chlorotis, which had subpopulations established in nine pest-free sites by translocations over the last 10 years (four of which are fenced). These translocations have been so successful that the species has now been moved from the status of Nationally Endangered to Recovering (Hitchmough, 2013), although it is still listed 
as Endangered on the IUCN Red List until the increasing population trend is consolidated (Birdlife International., 2012a). Finally, a substantial portion of the known population of the Critically Endangered taiko Pterodroma magentae occupy burrows within the fenced Sweetwater Conservation Covenant on Chatham Island (Miskelly et al., 2009), so the subpopulation inside the fence must be included in the IUCN Red List assessment of this species. It is likely that large Australian conservation fenced areas would thus satisfy the New Zealand definition of self-sustaining, if it is only the ecosystem that is managed via fence maintenance and incursion control (IUCN Standards and Petitions Subcommittee, 2014).

With the exception of the two semi-urban National Parks (Table Mountain and Garden Route) and the international borders of three transfrontier parks (Kgalagadi, Kruger, and Mapungubwe), all of South Africa's national parks and stateowned protected areas are fenced. Subpopulations within such fenced, "mainland island" reserves are included in assessments by global Red List authorities in South Africa. Excluding these from global status assessments would reduce the area of occupancy and abundance of numerous key threatened species, including African wild dogs Lycaon pictus (5\% reduction in abundance based on global IUCN Red List assessment reports), lions Panthera leo (4\%) and cheetahs Acinonyx jubatus (8\%). The isolated nature of the subpopulations they protect means that the self-sustainability of these subpopulations could be questioned. Whether these fenced subpopulations are selfsustaining is related to the size of the reserve and the species' area requirements. For example, almost 600 elephants inhabit the fenced Addo Elephant National Park but this is unlikely to be self-sustaining in the long-term without the provision of artificial water points and genetic supplementation given its founder population was fewer than ten individuals (Whitehouse and Hall-Martin, 2000; Gough and Kerley, 2006). The Kruger National Park's African wild dog population is below the effective population size considered necessary to avoid loss of genetic diversity (Traill et al., 2007) and so is incorporated into South Africa's "managed metapopulation" of wild dogs (Davies-Mostert et al., 2009) (albeit not in practice yet). South Africa's cheetahs are being similarly managed (Lindsey et al., 2011). Other predators reintroduced within South Africa face a similar management plight. These examples illustrate that many Red Listed species in South Africa occur behind conservation fences and are managed intensively yet they are included in the IUCN Red List assessments, in contrast to those species in Australia that occur in similar circumstances. Furthermore, there are challenges in obtaining robust information from some intensively managed, smaller conservation reserves.

Finally, the Arabian oryx Oryx leucoryx was driven Extinct in the Wild in 1972, but captive breeding and reintroduction have improved its status to vulnerable $(\sim 1000$ individuals; IUCN SSC Antelope Specialist Group, 2011). Yet the subpopulation in Oman's 282,400 ha Al Wusta Wildlife Reserve is fenced to reduce poaching ( $\mathrm{Al}$ Jahdhami et al., 2010). The remaining $\sim 500$ scimitar-horned oryx $O$. dammah are similarly fenced in various subpopulations such that "none is eligible for consideration ... for [IUCN Red List] assessment purposes" (IUCN SSC Antelope
Specialist Group, 2013). Many forest reserves in Kenya are being fenced, including Mt. Kenya and the Aberdares (Pearce, 2015), and this raises questions about the inclusion of the important wildlife subpopulations they hold being included in Red List assessments. These examples highlight the international nature of conservation fencing and illustrate the need for guidance on their inclusion for Red List assessors.

It is evident that experts from different countries include or exclude fenced subpopulations depending on their interpretation on whether the subpopulation is self-sustaining. This bias is due to a lack of quantitative thresholds on when management intensity negates the wildness of subpopulations of a particular species. For example, the European bison Bison bonasus was saved from extinction following the First World War when Polish conservationists used captive bred animals to re-establish a population in Białowieża Primeval Forest (Krasiñska and Krasi, 2007). The founder population of eight had reached 439 individuals in the forest in 2007 (Hayward et al., 2011), but this population is bounded by an international border fence and inhospitable farm lands (Kowalczyk et al., 2013). This is therefore essentially an isolated subpopulation that is heavily managed by feeding over winter and culling over summer (Hayward et al., 2011). While this subpopulation may not decline to extinction within 10 years without this management, it clearly can be interpreted as being intensively managed, yet is included in the Red List assessment (Olech, 2008). Similarly, the USA's Kirtland's warbler Dendroica kirtlandii has been downlisted to Near Threatened following intensive fire management to increase breeding habitat and cowbird control to reduce parasitism, all within the confines of the species distribution to the 526,100 ha Kirtland's Warbler Management Area (Birdlife International., 2012b). Finally, all protected areas in Western Australia (and most throughout southern Australia) rely on intensive conservation management by way of introduced red fox Vulpes vulpes control over 3.4 million ha, to sustain their threatened native species.

Such intensive management actions are designed to ensure persistence of species such that they are included in the global Red List assessments as extant. Without these interventions, there is a strong likelihood that numerous species would become increasingly threatened on the Red List, yet this very management may exclude these subpopulations from inclusion in the assessment because they are no longer considered selfsustaining. Thus, there is a strong need for the IUCN to develop both general and taxa-specific quantitative thresholds on what determines a wild and self-sustaining subpopulation, and both state and privately protected areas should be subject to revised guidelines to align assessments between regions and reduce subconscious bias.

Similarly, management actions need to be qualified by their effects on the resilience of the population (Redford et al., 2011). Metapopulation management is management intensive yet is required to maintain genetic diversity in small, isolated subpopulations. Conversely, translocations without a metapopulation plan are likely to homogenize species distributions (Spear and Chown, 2008). Similarly, although conservationists may intensively manage subpopulations (e.g., 
pre-emptive vaccination against rabies for a wild dog pack), many wildlife ranchers will intensively manage at the individual level (i.e., regular veterinary care) or artificially select individuals for desirable trophy hunting traits (increased horn length or rare color morph) thus directly altering the genotypic and phenotypic traits of individuals and undermining the evolutionary trajectory, adaptive potential and, ultimately, wildness of the subpopulation. Indeed, it is not unusual for highly threatened species, like black rhinoceros Diceros bicornis or African wild dogs, to receive individual veterinary care in most South African national parks. Consequently, including fenced subpopulations is not simply a question of being fenced or not but is dependent on the type, scale, frequency, and effects of the suite of management interventions.

\section{Defining Benchmark Distributions}

The second technical issue that is subject to bias is the definition of natural distribution range, and the subsequent inclusion of introduced subpopulations. The IUCN guidelines lack a definition of "natural range" and simply state that "wild subpopulations inside the natural range of the species [should be included]" (IUCN Standards and Petitions Subcommittee, 2014: 7). Such vagueness is often compounded by poor information on the distribution of a species (historical and present) and makes the issue vulnerable to inconsistency and bias. Although one assumes a natural range should be defined as the historical range (often before widespread human disturbance), how far back do we define human disturbance? If we use the advent of mechanized agriculture, we ignore long-term late Pleistocene species declines, which limits the applicability of rewilding because the potential list of indigenous species for a given region is diminished. More historical benchmarks offer the opportunity to include species that are currently excluded from Red List assessment because they have been domesticated and are now considered extinct (e.g., dromedary camel Camelus dromedarius, or the aurochs Bos primigenius). Conversely, many stakeholders argue that climate change negates the use of "natural range" as a benchmark and undermines place-based reintroduction or restoration (Sandler, 2012), an argument that can equally be used to help introduce species to future suitable habitats or to expand the scope of trade and thus commercial interests.

Confusion over the range limits (past and future) of species affect the baselines against which they are assessed and thus affect whether subpopulations are considered introduced or reintroduced. Introduced subpopulations are rarely considered in the Red List assessments (but some benign introductions are), however reintroduced subpopulations often are. The IUCN provide the following guidelines on including "introduced" subpopulations (IUCN Standards and Petitions Subcommittee, 2014: 7):

1. If "the known or likely intent of the introduction was to reduce the extinction risk of the taxon being introduced. In cases where the intent is unclear, the assessors should weigh the available evidence to determine the most likely intent." Stakeholders can introduce conscious bias here by arguing that the introduction was performed for conservation although the intention is truly commercial. If the distinction matters, and presumably it does as a species introduced far outside its known suitable habitat may either adversely or positively affect the local ecosystem (e.g., Waldram et al., 2008; Hayward, 2009a), then we need clearer guidelines by which to gauge intent and to not alienate stakeholders.

2. If "the introduced subpopulation is geographically close to the natural range of the taxon. What is considered geographically close enough should be determined by the assessor, considering factors such as the area of the natural range, the nature of the landscape separating the natural and the introduced range, and whether the taxon could have dispersed to the introduced range without the effects of human impacts such as habitat loss and fragmentation. For example, an introduced subpopulation in a continent distant from the natural range would not qualify. On the other hand, most introduced subpopulations within the same ecoregion as the natural range would qualify."

Again, this vague guideline can be used to justify the establishment of a subpopulation well-outside the benchmark distribution by employing the climate change trope, especially if the habitat has already been modified by management to suit the target species (via vegetation management or predator control for example). Once such an introduced subpopulation is established and becomes part of the benchmark distribution, it is a series of small logical steps that a savannah species, such as sable antelope (Hippotragus niger), could and should exist in the fynbos biome (especially as an ad hoc justification of pre-existing introductions sensu, Spear and Chown, 2009). If Red List assessments are ultimately used to measure the state of biodiversity, then the reduction of beta diversity through unnecessary and homogenizing introductions must be carefully considered.

The vagueness in defining natural or benchmark ranges also impacts the accuracy and consistency of Red List assessments, by introducing subconscious bias. For example, the Eurasian lynx Lynx $\operatorname{lynx}$ is listed as Regionally Extinct in Liechtenstein and described as never having occurred in nearby Belgium or The Netherlands, or the UK (Breitenmoser et al., 2008). Yet these countries had populations of lynx within recorded historical times (Hetherington, 2006). Any human-managed movement of lynx into these countries could be defined as an introduction (as suitable habitat within its core range states still remains and thus the definition of a benign introduction is not met) and the animals within will not be considered in the Red List assessments. Another example is the musk ox Ovibos moschatus population on Wrangel Island that is considered introduced, however the island is likely to have sustained a population during the Holocene (Gunn and Forchhammer, 2008). The European bison is recorded as being reintroduced to 30 countries (Pucek, 2004), yet only seven countries are listed as having native populations in the Red List, with the subpopulation in Kyrgyzstan listed as introduced (Olech, 2008). Given the wealth of historical records of European bison, it is hard to see what the dispersal barrier was for the species given its ability to persist 
in Kyrgyzstan today. Lastly, the original (1788) distributions of Australian fauna are based on a small number of early explorers journal records (e.g., numbat Myrmecobius fasciatus-Friend, 2013). Any movement of species beyond these minimal ranges could be, and often are, interpreted as introductions, whereas a more thorough understanding of these distributions (e.g., by way of local environmental knowledge that vastly increased the known range of the woylie; Burbidge et al., 1988) may reveal them to be reintroductions.

It is also not the isolation of "mainland islands" that is problematic. The mala Lagorchestes hirsutus was once widespread across the spinifex sand dunes of the Australian deserts, but is now classified as Extinct in the Wild. Thirty individuals were marooned on Trimouille Island, off the Western Australian coast, in 1998 (Richards et al., 2008) and the subpopulation there is now thought to exceed 120 individuals (Burbidge et al., 2014). This subpopulation is included in the IUCN Red List assessment, even though it is introduced, however several other mainland island populations are not included, even though they are within the original range of the species (Richards et al., 2008).

In South Africa, the definition of the natural indigenous range of many antelope species is in fierce contention, as stakeholders with commercial interests seek to relax the definition so that trade and translocation can occur without restriction, whereas others seek to prevent potential habitat degradation, hybridization, and alien invasion from such translocations (for a review of this see Spear and Chown, 2008). Such conflict introduces conscious bias to the assessments. Utilitarians argue that climate change will negate historical views on distribution and that enabling species to access new habitats will only engender resilience to the populations that persist (e.g., novel ecosystems; Hobbs et al., 2006). Conversely, others argue that even with the effects of climate change, some species will never occur naturally in certain habitats and, by indiscriminately establishing subpopulations of species, beta diversity will ultimately be degraded (e.g., as mentioned above, sable antelope would never naturally occur in the fynbos). Thus, in this particular information vacuum, assessors can introduce conscious bias to leverage an agenda of deregulating trade. Clearly, some compromise is needed to accommodate for the novel ecosystems and possible range shifts necessitated by a rapidly changing climate but defining and calibrating these within the bounds of what is capable from the dispersal capacities and habitat tolerance of the species needs to be incorporated into the Red List guidelines, such that beta diversity is sustained in a shifting mosaic of communities, rather than forced homogenization of fauna that increases numbers of the focal species that may detract from broader biodiversity.

\section{Problems Related to the IUCN Red List Guidelines and Policy}

Three examples from the recent revision of the national Red List of South African mammals serve to highlight the aforementioned sources of bias and how this bias might be mitigated. The bontebok Damaliscus pygargus pygargus, Cape mountain zebra Equus zebra zebra and black wildebeest Connochaetes gnou are South African endemics and thus the national assessment is also the global assessment, which highlights the crucial need to align the thinking of in situ experts with the SSC Specialist Groups.

Firstly, whereas all three assessments include private fenced subpopulations in the assessments, this is not consistent across other antelope assessments in South Africa. For example, privately fenced subpopulations are not included for sable due to reports that most, if not all, private subpopulations are intensively managed and selectively bred to the point that they have no conservation value. Conversely, private fenced subpopulations are included in the other assessments because the assessors suspect they are not intensively managed. In all cases, the decision pivots subjectively on what the assessors feel constitutes intensive management and thus represents subconscious bias. This has been resolved in the current South African national Red List revision by conducting sensitivity analyses on permutations of the data to assess whether the assessment is robust to including or excluding questionable subpopulations and also by actively engaging the relevant SG to provide the most experienced and objective guidance, thereby aligning the national assessments with current best practice at the global scale. To solve this in the long-term, however, more case studies need to be published and the relevant SGs should engage regularly with local experts to align and refine the thresholds of intensive management laid out by the IUCN guidelines Version 11.

For all three taxa, hybridization is a concern for some assessors who rely on the precautionary principle, but not for others. The latest IUCN guidelines simply state that "hybrids may not be included" in Red List assessments (IUCN Standards and Petitions Subcommittee, 2014: 6). However, what evidence is strong enough to define a hybrid and what proportion of hybrid individuals in a subpopulation is sufficient to preclude the subpopulation is under contention. For example, the total black wildebeest population is currently estimated at around 25,000 individuals and much of this is outside its native range (Lindsey et al., 2013). However, the majority of the population in South Africa's Free State exhibits morphometric features characteristic of hybridization with blue wildebeest, resulting from both species being kept sympatrically in fenced reserves and game ranches (Ackermann et al., 2010). Three key issues are debated: the ability to detect hybrids, the severity of the threat itself, and also the management implications of culling putative hybrids (Grobler et al., 2011); all of which potentially introduces conscious bias to the assessment. The uncertainty of course has consequences for the assessment. If we were to exclude all private and formally protected subpopulations that might contain hybrids and focus only on known "pure" subpopulations, the total population size would dip to below 1000 mature individuals, making the species Vulnerable D1, whereas including all or most of the potentially affected subpopulations yields a Least Concern listing. This issue is further exemplified with the Endangered blackeared miner Manorina melanotis that is threatened by genetic introgression through hybridization with the yellow-throated miner M. flavigula in the Australian mallee and so birds with hybrid morphology are culled (Birdlife International., 2013) (a challenging process when less than 10 shooters in Australia are capable of correctly identifying hybrid individuals). Thus, the lack of specific guidelines on what evidence is strong enough to constitute a hybrid, combined with inadequate information 
on what proportion of the total population is affected by hybridization and whether the existence of practical management interventions (as opposed to largely unmanageable threats such as habitat loss) reduces the severity of the threat and thus risk tolerance, introduces both subconscious and conscious biases.

Cape mountain zebra are preliminarily listed as Near Threatened using the precautionary principle (despite the population growing at nearly $11 \% \mathrm{pa}$ ), however if all the private fenced subpopulations were included, the species would be listed as Least Concern (Hrabar and Kerley, 2013). The assessors are currently split over whether these private subpopulations are managed intensively; whether they constitute viable subpopulations (breeding units); and whether the lack of a metapopulation plan will threaten genetic diversity (although there are translocations between properties). This conundrum will only get worse in the future, as the number of privatelyowned subpopulations is growing rapidly, while the number of state-owned subpopulations is static.

Similarly, the bontebok status could be Endangered or Least Concern based on permutations of including fenced subpopulations that may or may not be intensively managed and/or hybridized (van der Walt et al., 2013). Including or excluding such subpopulations not only results from the ambiguity of the current IUCN guidelines (subconscious bias), but also conflicts between utilitarian/commercial ("if it pays, it stays") vs. purist/preservationist conservation viewpoint (conscious bias)_some assessors prioritize genetic purity while others focus simply on numbers. The bontebok assessment is similarly confounded by whether to limit the assessment to the indigenous natural range (as defined by historical records), which is estimated at $10,406 \mathrm{~km}^{2}$ in extent (Kerley et al., 2003), or to include the extended distribution range (as defined by generally similar habitat types within the Western Cape), which adds $15,156 \mathrm{~km}^{2}$ to the extent, and was motivated due to the limited availability of habitat (after agricultural transformation) within the indigenous range. Some assessors feel that limiting the assessment to the indigenous range is best because it preserves the evolutionary trajectory of the subspecies, while others feel including the extended range is correct because it offers a proactive mechanism for increased population growth of the subspecies through engaging private landowners. This debate is essentially a debate over what constitutes successful and ideal conservation approaches of vertebrates vs. the "use or lose it" argument (Redford et al., 2011; Soule, 2013), and thus introduces significant conscious bias into the assessments. This has implications for how the species are managed into the future as their classification on the Red List may determine the nature of any movement restrictions imposed by governments (Cousins et al., 2010).

\section{Solutions to Improve the IUCN Red List Guidelines}

To mitigate the root cause of the biases we describe above, the next version of the IUCN guidelines should provide specific and quantified thresholds on the following:
1. Permissible management actions and frequencies: What management actions are acceptable for a fenced subpopulation to be considered self-sustaining (and thus wild), and at what frequency can interventions be applied, is critical knowledge. Currently there is a paradox implicit in the guidelines: subpopulations that are not self-sustaining because they are intensively managed are excluded, yet many threatened populations are not self-sustaining in the wild (because they will not recruit due to Allee effects, for example; Courchamp et al., 2000) and thus require intensive management, yet are still included. Even subpopulations of ungulates in very large conservation areas such as the Kruger National Park in South Africa may be at risk (Nicholls et al., 1996). This paradox can be resolved by delineating between short-term survival at the individual level vs. long-term resilience at the subpopulation level: if a subpopulation or individual would not survive in a system once human management is withdrawn, it cannot be considered wild or self-sustaining, unless the management action is directly mitigating a persistent anthropogenically-induced threat, such as illegal harvesting or predation from introduced predators (IUCN Standards and Petitions Subcommittee, 2014) where such subpopulations would be classed as "conservation dependent" (Redford et al., 2011). However, management that provides all the food needs of the subpopulation or ongoing veterinary care to all individuals (thereby undermining disease resistance in the long-term), such that withdrawal of management would lead to subpopulation decline even in the absence of immediate threats, should not be included. Conversely, intensive management aimed at enhancing the long-term resilience and adaptive capacity of the subpopulation/species (e.g., metapopulation management) is permissible (Figure 2).

2. Thresholds for hybridization: Defining the minimum data needed to determine a hybrid and what proportion of hybrids in a subpopulation preclude it from a Red List assessment. Defining the allowable management techniques through culling hybrid individuals, restocking and translocation (i.e., to allow for backcrossing; Champagnon et al., 2012) that can be used to lessen the severity of this threat.

3. Defining benchmark distributions: Defining the degree of flexibility in estimating natural distribution ranges, specifically whether ecological niche modeling and habitat assessments can be used to include subpopulations outside of previously accepted or variable benchmark distributions. This is especially important in view of climate change, which is set to redefine what constitutes the natural range of the species (Hobbs et al., 2006; Sandler, 2012). Defining the natural range of the species should thus accommodate potential range shifts and subpopulations existing outside the natural range but in broadly similar habitat should be included. This would also further reward well-managed private properties that can contribute to the conservation of such species. A real novel risk, however, is that of forcing the conservation of species into inappropriate habitats through weak ecological niche modeling and habitat assessments (Cromsigt et al., 2012; Kerley et al., 2012). Setting quantified limitations on such 


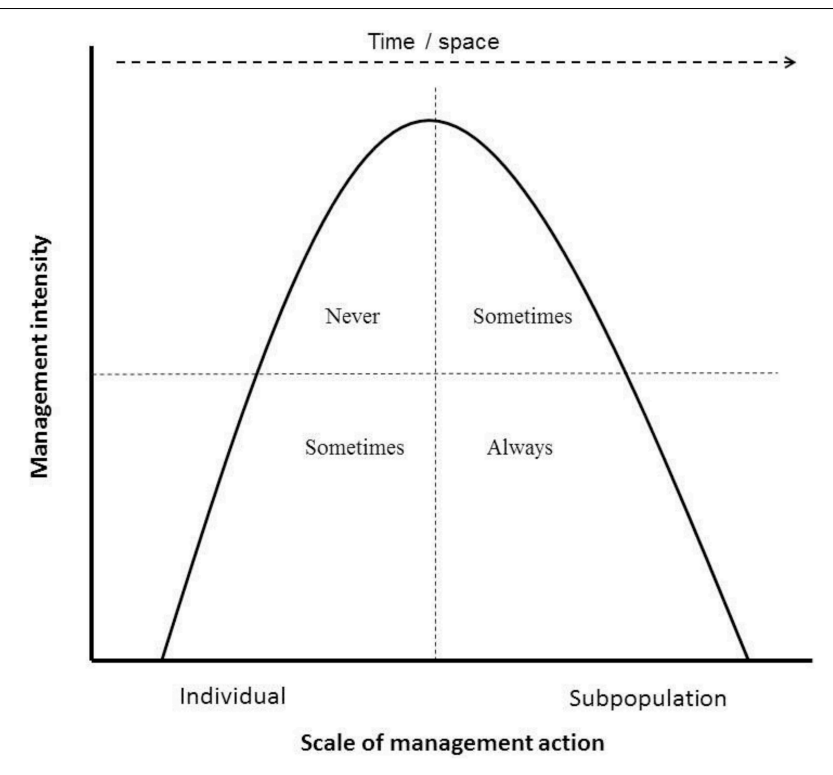

FIGURE 2 | The hypothetical relationship between management intensity and scale of management action related to the subpopulation's inclusion in the Red List. High-intensity management at the individual level (for example, selective breeding of Roan Antelope individuals within a herd) should never be included in the assessments. Low-intensity management at the individual scale can be included only if withdrawal of that intervention would not result in the decline of the subpopulation over the short term (c. 10 years). For example, providing supplementary food to a Sable herd during a drought is accepted, but not regularly providing supplementary food. High-intensity management aimed at the subpopulation scale can be included if the intervention is aimed at increasing the resilience of the overall populations. For example, the large flightless takahe Porphyrio hochstetteri, which has large area requirements and very low population sizes at individual sites requires managers to move individual animals between sites (currently including two fenced sites) to avoid inbreeding (i.e., metapopulation management), is a situation where the individuals are likely to survive in the protected area but in the long-term will need help to ensure genetic diversity. However, translocations and introductions that could lead to inbreeding or outbreeding depression or hybridization (i.e., not part of a metapopulation plan) are not included. Finally, low-intensity management aimed at the subpopulation level are always included in the Red List, for example, periodic supplementation of the subpopulation to enhance genetic diversity or broad habitat management to ensure key resource areas are sustained.

introductions is thus key for mitigating the impact of the species on local ecosystems.

Biases are more likely to occur when assessments are performed by individuals that are not part of SSC SGs (i.e., no internal auditing or norms and standards for the taxa), who have little Red Listing experience (subconscious bias), or in situations where the individuals can use the assessments to leverage personal values or agendas (conscious bias). For example, the assessors of the global Red List appear to introduce their personal values of fenced "mainland islands" into the process, as has been suggested in the USA Endangered Species Act 1973 (Harris et al., 2012). Similarly, the use of non-SG members to evaluate endemic mammal species in the recent national Red List revision for South Africa required multiple rounds of review from the SGs to remove both subconscious and conscious bias that had been introduced. These biases may in part be the result of ineffective communication during training workshops for national assessments, so assessing the effectiveness of information uptake at these workshops is important. Involving multiple stakeholders to obtain broader participation is undoubtedly beneficial to the Red Listing process through the integration of multiple sources of information; however, the addition of further quantitative criteria, combined with SG oversight, is required to prevent assessments from sliding into subjectivity. Consequently, when implementing and refining the revised guidelines, the SSC specialist groups could consider doing the following to counteract both subconscious and conscious bias (Figure 1):

1. To redress inconsistency in SG members between continents, publish case studies of difficult assessments and analyse how contentious issues were solved. These case studies should also be included in Red List assessor training workshops run by the IUCN Species Specialist Groups. We acknowledge that these do exist (http://www.iucnredlist.org/technicaldocuments/red-list-training/online-training), but they are not accredited and are hard to locate, and we recommend this become a formal part of assessor training.

2. To redress subconscious bias from non-SG members, elearning platforms should be established, with the aim to produce accredited assessors. Only those who have taken the course would be allowed to contribute to an assessment.

3. To redress conscious biases from non-SG members, a combination of implementing intervention 2, ensuring that all viewpoints are included, and ensuring the assessment is reviewed by a SG member should counteract the assessment from becoming a political tool.

\section{Conclusions}

It is important to note that we are not criticizing the current guidelines, but rather seek to further refine them as has occurred since their inception to maximize the transparency and objectivity of the process. For many species, the current criteria have worked well. However, as habitat loss continues to encroach on remaining wilderness areas, wildlife, particularly large mammal species, will increasingly be restricted to fenced areas, which will necessitate a more detailed discussion about their management (Ripple et al., 2015) and of what it means to conserve these species so their "wildness" quality is sustained (sensu Redford et al., 2011). In addition, as subpopulations of wildlife become smaller and more fragmented, increasingly intensive and diverse forms of management will be required. Ultimately the guidelines will need to set thresholds and targets to measure progress toward the ideal goal of conserving species and not simply reflecting our baseline progress-that of preventing extinction. Currently, aspects of the guidelines on fenced subpopulations and benchmark distributions are too ambiguous to consistently apply the criteria. The discrepancies in Red List assessments described above imply that without detailed guidance and sufficient data, assessors may rely on personal values and opinions to determine the status of species. Various 
issues in conservation are highly controversial (e.g., fencing for conservation) and strong personal opinions arise (Woodroffe et al., 2014). For fencing, these appear to be largely based on personal experience/values and rarely are underpinned with data (but see Packer et al., 2013). The Red List assessments need to transcend individual interpretation to ensure they are robust and standardized throughout the world. We propose that the guidelines should provide greater clarity on the definition of wild, self-sustaining populations and the threshold of management intensity that precludes fenced subpopulations as well as the definitions of benchmark distribution that guide the inclusion of introduced subpopulations. This will improve consistency in applying the data to the criteria and has been mandated in Resolution 4d arising from the World Conservation Congress in the Republic of Korea (WCC, 2012). Finally, this will also provide legitimacy to intensive conservation actions aimed at enhancing subpopulation resilience and adaptive capacity (e.g., metapopulation management) where, currently, many people

\section{References}

Ackermann, R. R., Brink, J. S., Vrahimis, S., and De Klerk, B. (2010). Hybrid wildebeest (Artiodactyla: Bovidae) provide further evidence for shared signatures of admixture in mammalian crania. S. Afr. J. Sci. 106, 1-4. doi: 10.4102/sajs.v106i11/12.423

Ahrends, A., Burgess, N. D., Gereau, R. E., Marchant, R., Bulling, M. T., Lovett, J. C., et al. (2011). Funding begets biodiversity. Divers. Distribut. 17, 191-200. doi: 10.1111/j.1472-4642.2010.00737.x

Al Jahdhami, M., Al-Mahdhoury, S., and Al Amri, H. (2010). "The re-introduction of Arabian oryx to the Al Wusta Wildlife Reserve in Oman: 30 years on," in Global Re-introduction Perspectives: 2011: More Case Studies from Around the Globe, ed P. S. Soorae (Abu Dhabi: IUCN Species Survival Commission's Reintroduction Specialist Group), 194-198.

Bakker, V. J., Baum, J. K., Brodie, J. F., Salomon, A. K., Dickson, B. G., Gibbs, H. K., et al. (2010). The changing landscape of conservation science funding in the United States. Conserv. Lett. 3, 435-444. doi: 10.1111/j.1755-263X.2010. 00125.x

Birdlife International. (2012a). "Anas chlorotis," in IUCN Red List of Threatened Species. Version 2014.3 Downloaded 01/06/2015 (Gland: IUCN). Available online at: http://www.iucnredlist.org/details/22728303/0

Birdlife International. (2012b). Dendroica Kirtlandii [Online]. Gland: IUCN. (Accessed 2/5/2014).

Birdlife International (2013). Manorina Melanotis [Online]. Gland: IUCN. (Accessed 2/5/2014).

Breitenmoser, U., Mallon, D., Von Arx, M., and Breitenmoser-Wursten, C. (2008). "Lynx lynx.," in IUCN Red List of Threatened Species Version 2014.2, (Gland: IUCN). Available online at: http://www.iucnredlist.org/details/12519/0 (Accessed September 11, 2014).

Burbidge, A. A., Johnson, K. A., Fuller, P. J., and Southgate, R. I. (1988). Aboriginal knowledge of the mammals of the central deserts of Australia. Aust. Wildl. Res. 15, 9-39. doi: 10.1071/WR9880009

Burbidge, A. A., and McKenzie, N. L. (1989). Patterns in the modern decline of Western Australia's vertebrate fauna: causes and conservation implications. Biol. Conserv. 50, 143-198. doi: 10.1016/0006-3207(89)90009-8

Burbidge, A., Woinarski, J., and Harrison, P. (2014). The Action Plan for Australian Mammals 2012. Melbourne: CSIRO PUBLISHING.

Butchart, S. H. M., Akcakaya, H. R., Kennedy, E., and Hilton-Taylor, C. (2006). Biodiversity indicators based on trends in conservation status: strengths of the IUCN red list index. Conserv. Biol. 20, 579-581. doi: 10.1111/j.15231739.2006.00410.x

Butchart, S. H. M., Stattersfield, A. J., Baillie, J., Bennun, L., Stuart, S. N., Akcakaya, H. R., et al. (2005). Using Red List Indices to measure progress towards the 2010 view them as beyond the realm of standard conservation actions because they are thought to incur more management cost and effort than unfenced areas (Scofield et al., 2011). The IUCN Red List is the most powerful tool for reporting biodiversity trends; continued refinement and implementation of the guidelines will only increase its utility.

\section{Acknowledgments}

This paper arose from discussions with Andrew Burbidge. We thank Guy Castley, Mike Hoffmann, Michael Bode, Harriet Davies-Mostert, and four referees for critical review of this manuscript and insightful discussions/suggestions on this topic. MC thanks the Scientific Authority of the South African National Biodiversity Institute, the Department of Environmental Affairs and the Norwegian Environment Agency for supporting the revision of the South African Red List of mammals. target and beyond. Philos. Trans. R. Soc. Lond. Ser. B Biol. Sci. 360, 255-268. doi: $10.1098 /$ rstb.2004.1583

Champagnon, J., Elmberg, J., Guillemain, M., Gauthier-Clerc, M., and Lebreton, J.-D. (2012). Conspecifics can be aliens too: a review of effects of restocking practices in vertebrates. J. Nat. Conserv. 20, 231-241. doi: 10.1016/j.jnc.2012.02.002

Chapple, D. G. (2010). "Oligosoma Otagense," in IUCN Red List of Threatened Species. Version 2014.3 Downloaded 01/06/2015, (Gland: IUCN). Available online at: http://www.iucnredlist.org/details/15260/0

Clarke, M. F., and Grey, M. J. (2010). "Managing an over-abundant native bird: the noisy miner (Manorina melanocephala)," in Temperate Woodland Conservation and Management, eds D. B. Lindenmayer, A. F. Bennett, and R. J. Hobbs, $115-126$.

Courchamp, F., Clutton-Brock, T. H., and Grenfell, B. (2000). Multipack dynamics and the Allee effect in the African wild dog, Lycaon pictus. Anim. Conserv. 3, 277-285. doi: 10.1111/j.1469-1795.2000.tb00113.x

Cousins, J. A., Sadler, J. P., and Evans, J. (2010). The challenge of regulating private wildlife ranches for conservation in South Africa. Ecol. Soc. 15:28. Available online at: http://dlc.dlib.indiana.edu/dlc/handle/10535/6027

Cromsigt, J. P. G. M., Kerley, G. I. H., and Kowalczyk, R. (2012). The difficulty of using species distribution modellingforthe conservation of refugee species-the example of European bison. Divers. Distribut. 18, 1253-1257. doi: 10.1111/j.1472-4642.2012.00927.x

Davies-Mostert, H. T., Mills, M. G. L., and Macdonald, D. W. (2009). "South Africa's wild dog Lycaon pictus meta-population management programme," in The Reintroduction of Top-order Predators, eds M. W. Hayward and M. J. Somers (Oxford: Blackwell Publishing), 10-42.

Delbridge, A., and Bernard, J. R. L. (eds.). (1995). The Macquarie Concise Dictionary. Sydney: Macquarie Library.

Friend, J. A. (2013). National Recovery Plan for the Numbat. Canberra, ACT: Department of Environment, Water, Heritage and the Arts.

Gough, K., and Kerley, G. I. H. (2006). Lack of density dependent regulation in Addo's elephant population. Oryx 40, 464-441. doi: 10.1017/S003060530 6001189

Grobler, J. P., Rushworth, I., Brink, J. S., Bloomer, P., Kotze, A., Reilly, B., et al. (2011). Management of hybridization in an endemic species: decision making in the face of imperfect information in the case of the black wildebeestConnochaetes gnou. Eur. J. Wildl. Res. 57, 997-1006. doi: 10.1007/s10344-0110567-1

Gummer, H., Taylor, G., Wilson, K.-J., and Rayner, M. J. (2015). Recovery of the endangered Chatham petrel (Pterodroma axillaris): a review of conservation management techniques from 1990 to 2010. Glob. Ecol. Conserv. 3, 310-323. doi: 10.1016/j.gecco.2014.12.006 
Gunn, A., and Forchhammer, M. (2008). "Ovibos moschatus," in IUCN Red List of Threatened Species. Version 2014.3 Downloaded 17/03/2015 (Gland: IUCN).

Harris, J. B. C., Reid, J. L., Scheffers, B. R., Wanger, T. C., Sodhi, N. S., Fordham, D. A., et al. (2012). Conserving imperiled species: a comparison of the IUCN Red List and U.S. Endangered Species Act. Conserv. Lett. 5, 64-72. doi: 10.1111/j.1755-263X.2011.00205.x

Hayward, M. W. (2009a). Conservation management for the past, present and future. Biodivers. Conserv. 18, 765-775. doi: 10.1007/s10531-0089436-y

Hayward, M. W. (2009b). The need to rationalize and prioritize threatening processes used to determine threat status in the IUCN Red List. Conserv. Biol. 23, 1568-1576. doi: 10.1111/j.1523-1739.2009.01260.x

Hayward, M. W., de Tores, P. J., Dillon, M. J., and Fox, B. J. (2003). Local population structure of a naturally-occurring metapopulation of the quokka (Setonix brachyurus Macropodidae: Marsupialia). Biol. Conserv. 110, 343-355. doi: 10.1016/S0006-3207(02)00240-9

Hayward, M. W., Kowalczyk, R., Krasiñski, Z. A., Krasiñska, M., Dackiewicz, J., and Cornulier, T. (2011). Restoration and intensive management have no effect on evolutionary strategies. Endanger. Species Res. 15, 53-61. doi: 10.3354/ esr00371

Hayward, M. W., Moseby, K. E., and Read, J. L. (2014). "The role of predator exclosures in the conservation of Australian fauna," in Carnivores of Australia, eds A. S. Glen and C. R. Dickman (Heidelberg, Melbourne, VIC: CSIRO Publishing), 363-379.

Hervieux, D., Hebblewhite, M., Stepnisky, D., Bacon, M., and Boutin, S. (2014). Managing wolves (Canis lupus) to recover threatened woodland caribou (Rangifer tarandus caribou) in Alberta. Can. J. Zool. 92, 1029-1037. doi: $10.1139 / \mathrm{cjz}-2014-0142$

Hetherington, D. A. (2006). The lynx in Britain's past, present and future. Ecos 27, 68-74. Available online at: http://www.citeulike.org/group/342/article/577202

Hitchmough, R. (2013). Summary of Changes to the Conservation Status of Taxa in the 2008-11 New Zealand Threat Classification System Listing Cycle (New Zealand Threat Classification Series 1). Wellington: New Zealand Department of Conservation.

Hitchmough, R., Anderson, B., Barr, J., Monks, J., Lettink, M., Reardon, J., et al. (2013). Conservation Status of New Zealand Reptiles, 2012 (New Zealand Threat Classification Series 2). Wellington: New Zealand Department of Conservation.

Hobbs, R. J., Arico, S., Aronson, J., Baron, J. S., Bridgewater, P., Cramer, V. A., et al. (2006). Novel ecosystems: theoretical and management aspects of the new ecological world order. Glob. Ecol. Biogeogr. 15, 1-7. doi: 10.1111/j.1466822X.2006.00212.x

Hrabar, H., and Kerley, G. I. H. (2013). Conservation goals for the Cape mountain zebra Equus zebra zebra-security in numbers? Oryx 47, 403-409. doi: 10.1017/ S0030605311002018

IUCN. (2001). IUCN Red List Categories and Criteria: Version 3.1. Gland; Cambridge: IUCN.

IUCN SSC Antelope Specialist Group (2011). "Oryx leucoryx," in IUCN Red List of Threatened Species. Version 2012 2, (Gland). Available online at: http://www. iucnredlist.org(Accessed November 26, 2012).

IUCN SSC Antelope Specialist Group (2013). "Oryx dammah" in IUCN Red List of Threatened Species. Version 2012 2, (Gland). Available online at: http://www. iucnredlist.org (Accessed May 26, 2013).

IUCN Standards and Petitions Subcommittee (2010). Guidelines for Using the IUCN Red List Categories and Criteria. (Gland: IUCN).

IUCN Standards and Petitions Subcommittee. (2014). Guidelines for Using the IUCN Red List Categories and Criteria, Version 11. Gland; Cambridge: IUCN. Available online at: http://www.iucnredlist.org/documents/RedListGuidelines. pdf.

Kerley, G. I. H., Kowalczyk, R., and Cromsigt, J. P. G. M. (2012). Conservation implications of the refugee species concept and the European bison: king of the forest or refugee in a marginal habitat? Ecography 35, 519-529. doi: 10.1111/j.1600-0587.2011.07146.x

Kerley, G. I. H., Pressey, R. L., Cowling, R. M., Boshoff, A. F., and Sims-Castley, R. (2003). Options for the conservation of large and medium-sized mammals in the Cape Floristic Region hotspot, South Africa. Biol. Conserv. 112, 169-190. doi: 10.1016/S0006-3207(02)00426-3

Kowalczyk, R., Krasiñska, M., Kamiñski, T., Górny, M., Struœ, P., HofmanKamiñska, E., et al. (2013). Movements of European bison (Bison bonasus) beyond the Białowieża Forest (NE Poland): range expansion or partial migrations? Acta Theriol. 58, 391-401. doi: 10.1007/s13364-013-0136-y

Krasiñska, M., and Krasiñski, Z. A. (2007). The European Bison: a Nature Monograph. Bialowieza: Mammal Research Institute, Polish Academy of Science.

Lindsey, P. A., Havemann, C., Lines, R. M., Price, A., Retief, T., Rhebergen, T., et al. (2013). Benefits of wildlife-based land uses on private lands in Namibia and limitations affecting their development. Oryx 47, 41-53. doi: 10.1017/S0030605311001049

Lindsey, P. A., Tambling, C. J., Brummer, R., Davies-Mostert, H. T., Hayward, M. W., Marnewick, K. A., et al. (2011). Minimum prey and area requirements of cheetahs: implications for reintroductions and management of the species as a managed metapopulation. Oryx 45, 587-599. doi: 10.1017/S003060531000150X

Lynch, M., and O'hely, M. (2001). Captive breeding and the genetic fitness of natural populations. Conserv. Genet. 2, 363-378. doi: 10.1023/A:1012550620717

Mace, G. M., Collar, N. J., Cooke, J., Gaston, K. J., Ginsberg, J. R., Leader-Williams, N., et al. (1992). The development of new criteria for listing species on the IUCN Red List. Species 19, 16-22.

Mace, G. M., and Lande, R. (1991). Assessing extinction threats: toward a reevaluation of the IUCN threatened species categories. Conserv. Biol. 5, 148-157. doi: 10.1111/j.1523-1739.1991.tb00119.x

Miskelly, C. M., Dowding, J. E., Elliott, G. P., Hitchmough, R., Powlesland, R. P., Robertson, H. A., et al. (2008). Conservation status of New Zealand birds, 2008. Notornis 55, 117-135. Available online at: https://www.researchgate. net/profile/R_Scofield/publication/227943582_Conservation_status_of_New_ Zealand_birds_2008/links/00b4952ba0ba3caf4d000000.pdf

Miskelly, C. M., Taylor, G. A., Gummer, H., and Williams, R. (2009). Translocations of eight species of burrow-nesting seabirds (genera Pterodroma, Pelecanoides, Pachyptila and Puffinus: Family Procellariidae). Biol. Conserv. 142, 1965-1980. doi: 10.1016/j.biocon.2009.03.027

Nicholls, A., Viljoen, P., Knight, M., and van Jaarsveld, A. (1996). Evaluating population persistence of censused and unmanaged herbivore populations from the Kruger National Park, South Africa. Biol. Conserv. 76, 57-67. doi: 10.1016/0006-3207(95)00094-1

Olech, W. (2008). "Bison bonasus," in IUCN Red List of Threatened Species, Downloaded on 29 October 2012 (Gland: IUCN). Available online at: http:// www.iucnredlist.org

Packer, C., Loveridge, A. J., Canney, S., Caro, T. M., Garnett, S. T., Pfeifer, M., et al. (2013). Conserving large carnivores: dollars and fence. Ecol. Lett. 16, 635-641. doi: $10.1111 /$ ele.12091

Pearce, F. (2015). Fencing up wildlife in Kenya's forests. New Sci. 3010. doi: $10.1016 / \mathrm{s} 0262-4079(15) 60387-6$

Powell, A. N., and Cuthbert, F. J. (1993). Augmenting small populations of plovers: an assessment of cross-fostering and captive-rearing. Conserv. Biol. 7, 160-168. doi: 10.1046/j.1523-1739.1993.07010160.x

Pucek, Z. (2004). European Bison: Status Survey and Conservation Action Plan. Gland: IUCN.

Reardon, J., Whitmore, N., Holmes, K. M., Judd, L. M., Hutcheon, A. D., Norbury, G., et al. (2012). Predator control allows critically endangered lizards to recover on mainland New Zealand. N. Z. J. Ecol. 36, 141-150. Available online at: http://www.jstor.org/stable/24060839?seq=1\#page_scan_tab_contents

Redford, K. H., Amato, G., Baillie, J., Beldomenico, P., Bennett, E. L., Clum, N., et al. (2011). What does it mean to successfully conserve a (vertebrate) species? Bioscience 61, 39-48. doi: 10.1525/bio.2011.61.1.9

Richards, J., Morris, K. D., Friend, J. A., and Burbidge, A. A. (2008). "Lagorchestes hirsutus," in IUCN Red List of Threatened Species. Version 2014.3 Downloaded 17/03/2015 (Gland: IUCN).

Ripple, W. J., Newsome, T., Wolf, C., Dirzo, R., Everatt, K. T., Galetti, M., et al. (2015). Collapse of the world's largest herbivores. Sci. Adv. 1:e1400103. doi: 10.1126/sciadv. 1400103

Rodrigues, A. S. L., Pilgrim, J. D., Lamoreux, J. F., Hoffman, M., and Brooks, T. M. (2006). The value of the IUCN Red List for conservation. Trends Res. Ecol. Evol. 21, 71-76. doi: 10.1016/j.tree.2005.10.010

Sandler, R. L. (2012). The Ethics of Species: An Introduction. Cambridge, UK: Cambridge University Press.

Scofield, R. P., Cullen, R., and Wang, M. (2011). Are predator-proof fences the answer to New Zealand's terrestrial faunal biodiversity 
crisis? N.Z.J. Ecol. 35, 312-317. Available online at: http://www.jstor. org/stable/24060745?seq=1\#page_scan_tab_contents

Short, J. (2009). The Characteristics and Success of Vertebrate Translocations within Australia. (Canberra, ATC: Department of Agriculture, Fisheries and Forestry).

Soule, M. (2013). The "New Conservation." Conserv. Biol. 27, 895-897. doi: $10.1111 /$ cobi. 12147

Spear, D., and Chown, S. L. (2008). Taxonomic homogenization in ungulates: patterns and mechanisms at local and global scales. J. Biogeogr. 35, 1962-1975. doi: 10.1111/j.1365-2699.2008.01926.x

Spear, D., and Chown, S. L. (2009). The extent and impacts of ungulate translocations: South Africa in a global context. Biol. Conserv. 142, 353-363. doi: 10.1016/j.biocon.2008.10.031

Taggart, D. A., Schultz, D., White, C., Whitehead, P., Underwood, G., and Phillips, K. (2005). Cross-fostering, growth and reproductive studies in the brushtailed rock-wallaby, Petrogale penicillata (Marsupialia: Macropodidae): efforts to accelerate breeding in a threatened marsupial species. Aust. J. Zool. 53, 313-323. doi: 10.1071/ZO05002

Traill, L. W., Bradshaw, C. J. A., and Brook, B. W. (2007). Minimum viable population size: a meta-analysis of 30 years of published estimates. Biol. Conserv. 139, 159-166. doi: 10.1016/j.biocon.2007. 06.011

van der Walt, J., Nel, L. H., and Hoelzel, A. R. (2013). Differentiation at mitochondrial and nuclear loci between the blesbok (Damaliscus pygargus phillipsi) and bontebok (D. p. pygargus): implications for conservation strategy. Conserv. Genet. 14, 243-248. doi: 10.1007/s10592-0120435-x

Waldram, M. S., Bond, W. J., and Stock, W. D. (2008). Ecological engineering by a mega-grazer: white rhino impacts on a South African savanna. Ecosystems 11, 101-112. doi: 10.1007/s10021-007-9109-9

WCC. (2012). Resolutions of the World Conservation Congress, Jeju, Republic of Korea (Jeju: World Conservation Congress).

Whitehouse, A. M., and Hall-Martin, A. (2000). Elephants in Addo Elephant National Park, South Africa: reconstruction of the population's history. Oryx 34, 46-55. doi: 10.1017/S0030605300030891

Woodroffe, R., Hedges, S., and Durant, S. M. (2014). To fence or not to fence. Science 344, 46-48. doi: 10.1126/science.1246251

Conflict of Interest Statement: The authors declare that the research was conducted in the absence of any commercial or financial relationships that could be construed as a potential conflict of interest.

Copyright (C) 2015 Hayward, Child, Kerley, Lindsey, Somers and Burns. This is an open-access article distributed under the terms of the Creative Commons Attribution License (CC BY). The use, distribution or reproduction in other forums is permitted, provided the original author(s) or licensor are credited and that the original publication in this journal is cited, in accordance with accepted academic practice. No use, distribution or reproduction is permitted which does not comply with these terms. 